\title{
Epidemiology of violence and mental illness
}

\author{
KENNETH TARDIFF
}

Most of the studies of violence and mental illness have involved the assessment of patients in treatment. There are few that have assessed untreated prevalence of violence. One study of untreated prevalence used data from the Epidemiological Catchment Area (ECA) survey which conducted structured interviews of persons living in several cities in the United States from 1980 to 1983 (Swanson et al. 1990). The Diagnostic Interview Schedule (DIS) was used for diagnosis and 5 DIS items for antisocial personality disorder, which are self-reports of physical violence toward other persons, was used as a measure of violence. Persons with one or more psychiatric diagnoses were more likely than persons without a psychiatric diagnosis to report having been violent in the year preceding the survey. There were $2.05 \%$ of the persons without a psychiatric diagnosis reporting violence compared to roughly $12 \%$ reporting violence with schizophrenia, bipolar disorder, and other major mental disorders and $35 \%$ reporting violence with a substance abuse diagnosis.

Another untreated prevalence study used data about a Swedish cohort of persons born in 1953 (Hodgins, 1992). Men with a mental disorder were 4 times more likely to be convicted of a violent crime than men without a mental disorder. Women with a mental disorder were 27 times more likely than women without a mental disorder to be convicted of a violent crime. Thus it appears that having a mental disorder does place one at higher risk for violence than persons without a mental disorder.

There have been numerous studies of violence by psychiatric patients before hospitalization, during hospitalization, after hospitalization and while in treatment in the community. Unlike the untreated

Indirizzo per la corrispondenza: Professor K. Tardiff, Department of Psychiatry, Box 140, Weill Medical College of Cornell University, 525 East 68th Street, New York 10021 (USA).

Fax: 212-746-8988

E-mail: kjtardif@mail.med.comell.edu prevalence studies they did not answer the question as to whether persons with mental illness are more violent than the general population. They sought to delineate which types of mental illness pose an increased risk for violence and why. The rest of this paper will describe these studies in regard to the mental disorders which are more commonly associated with violence by psychiatric patients.

Schizophrenia has been found to be associated with increased violence by psychiatric patients. Four different studies in which patients were interviewed during hospitalization in regard to violence just before admission found that patients with schizophrenia were more likely than patients with other disorders to have been violent (Craig, 1982; Tardiff, 1984; Rossi et al. 1986; Binder \& McNiel, 1988). Tardiff (1984) differentiated paranoid from non-paranoid schizophrenia and found no difference in rates violence and type of schizophrenia. However, Krakowski et al. (1986), points out in his review of other studies of inpatient violence and violence before admission that 4 studies reported higher rates of violence among paranoid schizophrenics, 2 studies found more violence among non-paranoid schizophrenics and 1 study found no difference between type of schizophrenia and violence. Two studies of patients living in the community found that a diagnosis of schizophrenia was related to increased risk of violence (Swanson et al. 1990, Link et al. 1992). In both, drug abuse was found to increase further the risk of violence among schizophrenic patients.

Studies of patients who were violent in psychiatric hospitals have found that schizophrenia is associated with increased violence (Tardiff \& Sweillam, 1982; Convit et al. 1988, Lee et al. 1989, Tam et al. 1996). Others have found that psychosis in the form of delusions and hallucinations plays a major role in violence by schizophrenic inpatients (Lowenstein et al. 1990, Benjaminsen et al. 1996, Arango et al. 1999). Taylor $(1986,1997)$ has explored the role of psychosis, namely delusions and hallucinations respectively, in violence by psychiatric patients. Delusions, particularly 
paranoid delusions, cause violence by schizophrenic patients but so do non-paranoid delusions, for example erotic delusions about the victim. Hallucinations also can cause violence by patients (Humphreys et al., 1992). The role of command hallucinations, where voices in auditory hallucination tell the patient to attack the victim, and violence is unclear (Junginger, 1995, Rogers et al., 1988, Hellerstein et al., 1987). Studies are conflicted in this matter, some finding that command hallucinations do result in violence while others find that patients ignore command hallucinations.

It is important to recognize that schizophrenic patients can be violent for reasons other than psychosis per se. Violence by schizophrenic patients may be due to comorbid alcohol or drug abuse (Lindqvist \& Allebeck, 1990; Swanson et al., 1990). Violence due to alcohol and drug abuse is discussed later in this paper. There may be a concurrent neurologic disorder which results in a low threshold for violence (Krakowski et al., 1989). These will be discussed later in this paper. Mentally retarded schizophrenic patients may resort to violence in response to frustration either in response to demands from family or staff or from the inability to verbalize their needs and conflicts.

Comorbid antisocial or borderline personality disorders increase the potential for violence among patients with major mental disorders (Swanson et al., 1990; Geller 1980). Violence can be manipulative, used to control or to express anger by these patients and not be related to the schizophrenic disorder itself.

Patients in a manic episode have been found to be more violent than some other types of patients (Tardiff, 1984; Binder \& McNiel, 1988; Janofsky et al., 1988). Violence usually occurs during the acute phase of the manic state and is often associated with psychosis and/or gross disorganization of thoughts and/or behavior (Miller et al., 1993; Yesavage, 1983). Targets of violence are often random in these cases. Manic patients who are more intact are violent when they feel restricted or when limits are being set by staff.

Patients with personality disorders have an increased risk of violence. The author found increased violence among patients with personality disorders 2 weeks before admission to a hospital and 2 weeks after discharge (Tardiff et al.,1997a; Tardiff et al., 1997b). Violence was increased among patients with personality disorders who presented to outpatient clinics for evaluations (Tardiff \& Koenigsberg, 1985). Miller et al. (1993) found patients with personality disorders have increased rates of violence in hospitals as well. The two types of personality disorders most likely to be associated with violence are the antisocial and borderline personality disorders (Eronen et al.,1996; Raine, 1993).

Individuals with antisocial personality disorder have a disregard for and violation of the rights of others, including violence which is a criteria for diagnosis of antisocial personality disorder (American Psychiatric Association, 1994). They tend to be irritable and repeatedly get into physical fights or otherwise attack others including spouses and children (Bland \& Orn, 1986). They destroy property, steal, harass others, and are involved in other criminal activities. They are impulsive and tend not to plan ahead (Hare et al., 1990). Violence and other behaviors that violate the rights of others are not accompanied by remorse or fear of consequences of violence. Instead the violence is rationalized, for example, the victim is seen by these individuals as deserving the violence. Decisions are made quickly without thinking of the consequences to self or others.

Individuals with borderline personality disorders have a pervasive pattern of instability in interpersonal relationships, self-image, emotional states, and marked impulsivity (American Psychiatric Association, 1994). They make efforts to avoid real or imagined rejection. They form intense relationships with caregivers or lovers and expect these persons to protect and rescue them (Benjamin, 1993). When the clinician or lover fails to live up to these unrealistic expectations, the individual with borderline personality disorder reacts with rage, verbal and/or physical violence, and suicidal behavior or other self-destructive behaviors. Impulsivity is severe in borderline personality and causes violence, suicide attempts as well as other self destructive behaviors (Stone, 1990). Individuals with borderline personality disorder have increased likelihood of having been physically or sexually abused as children (Perry \& Herman, 1993). Being physically abused as a child increases the risk of violence as an adult (Widom, 1989). This along with impulsivity and substance abuse contributes to the violent nature of those with borderline personality disorder.

Antisocial personality disorder and borderline personality disorder are both characterized by manipulation and dangerous behaviors. Individuals with both personality disorders display little remorse or concern for the damage their violence and other dangerous behaviors produce to other persons around them.

Intermittent explosive disorder is characterized by discrete episodes of loss of control resulting in serious violence towards persons or destruction of property

Epidemiologia e Psichiatria Sociale, 9, 4, 2000 
(American Psychiatric Association, 1994). This syndrome of episodic, explosive disorder was described decades age (Monroe, 1970;, Bach-y-Rita et al., 1971). The degree of violence is grossly out of proportion to any provocation or environmental stressor. Unlike patients with antisocial personality and borderline personality, after the episode of violence, the patient feels remorseful and/or embarassed about the violence. Between episodes of violence, the individual with intermittent explosive disorder may appear stable and a model citizen.

Posttraumatic stress disorder (PTSD) can have violence as one of many symptoms, along with depression, other anxiety disorders and substance abuse (American Psychiatric Association, 1994). Most studies have compared veterans with and without PTSD (Jordan et al., 1992; Lasko et al., 1994). Controlling for substance abuse and personality disorders, veterans with PTSD had higher levels of hostility, anger and physical violence. The violence may be diffuse as part of increased arousal with irritability and anger. On the other hand violence may be part of intense psychological distress in response to exposure to external cues that symbolize or resemble an aspect of the traumatic event.

The presence of alcohol and/or drug abuse increases the risk of violence. Among persons residing in the community, substance abuse is the disorder most frequently associated with violence and the presence of substance and major mental disorders increases the risk of violence way beyond what is found for the major mental disorders alone (Swanson et al., 1990). Patients in a psychiatric hospital violence reported violence just before admission twice as often for males and three times more often for females if they have a substance abuse disorder (Tardiff et al., 1997a). Patients are more likely to be violent in hospitals if they had a substance abuse disorder (Davis, 1991). Last, after discharge from hospitals, substance abuse was a major factor, alone and co-occurring with a major mental disorder, as to whether a patient was violent in the community (Stedman et al., 1998). Alcohol and each drug associated with violence will be discussed separately.

There is an extensive literature showing that the use of alcohol is associated with violence and violent crime (Collins \& Schlenger, 1988; Eronen et al., 1996; Murdock et al.,1990). The mechanism through which alcohol causes violence is complex. Disinhibition is one factor in that alcohol releases the drinker from inhibitions as to what is personally and socially acceptable, so that one acts, in this case violently, on angry urges and thoughts (Taylor \& Leonard, 1983).
Laboratory studies show that alcohol impairs the brain in thinking, thus the person under the influence of alcohol cannot fully use verbal and intellectual skills to deal with conflict or threatening situations (Peterson et al.,1990). Cognitive impairment from alcohol leads to violence in that the intoxicated person must rely on physical rather than verbal means of dealing with conflict. Cognitive impairment may also lead to misinterpretation of events or words, such as perceiving an insult from someone. Alcohol lowers levels of serotonin, which itself is associated with impulsive behaviors (Virkkunen \& Linnoila, 1990).

The surrounding social environment interacts with the intoxicated individuals to produce violence (Ito $e t$ al., 1996). There are provocations from family and friends, isolation resulting from chronic alcohol use, failure as work and lower self-esteem, all of which interact with the disinhibited, cognitively impaired brain to produce violence.

Cocaine users have been found to have anger and violent behavior during acute intoxication (Giannini et al., 1993; McCormick \& Smith, 1995). Smoking crack or intravenous use of cocaine produces a more rapid, intense intoxication than does intranasal use. Smoking or intravenous use produces a more intense "crash" during which there is severe craving for cocaine. A cycle of crash, smoking or intravenous injection to avoid a crash, followed by another crash etc. is set into motion. This produces severe intoxication and irritability and even a delirious state which can result in severe violence (Lowenstein et al., 1987; Mendoza \& Miller, 1992; Brody 1990). Cocaine can produce psychosis with paranoid delusions and hallucinations (Manschreck, 1988). In a psychotic state the cocaine user strikes out at persons whom the user believes is trying to hurt him/her. Although the acute effects of cocaine last for a day or so, psychosis with delusions may persist for days and result in violence. Cocaine users take alcohol or opiates to counteract the irritability, agitation and other disturbing side effects of cocaine. This leads to a situation where two or more substances combine to produce a greater degree of violence than the use of one substance alone (Denison et al., 1997; Salloum et al., 1996). Amphetamines used on a chronic basis and/or with high doses can produce paranoid delusional thinking similar to that of cocaine which is in turn associated with violence (Ellinwood, 1971).

Of the hallucinogens, phencyclidine (PCP) is the one most commonly associated with violence as well as selfdestructive and other bizzare behaviors. A study of patients presenting to an emergency department found 
that two-thirds of patients with PCP intoxication were agitated and/or violent (Bailey, 1979). Within an hour of oral use and five minutes if smoked or taken intravenously PCP produces impulsivity, unpredictability, grossly impaired judgement and violence. There may be delusional thinking or delirium. Since PCP is an anesthetic, it produces numbness or diminished response to pain which has resulted in cases where excessive force by police has been used in arresting persons intoxicated with PCP. As with cocaine there may be persistent psychopathology such as delusions for days after the use of PCP.

There have been a number of reports of violence by athletes using anabolic steroids (Choi et al., 1989; Pope \& Katz 1990; Schulte et al., 1993). These athletes were young men with no previous history of aggression or violence. After a month or so after routine use of anabolic steroids, they became irritable and violent. A study using a group of normal volunteers showed an increase of hostility and impulsivity in the subjects when they were given anabolic steroids (Su et al., 1993).

In the past a number of large studies of patients found that violence was increased among patients with an «organic mental disorder» a term no longer in use. Organic mental disorders are cases there was a gross physical or metabolic injury to the brain. Today we use the terms neurological and medical disorders instead of organic disorders.

Among psychiatric inpatients who were interviewed, patients with organic mental disorders, along with schizophrenia and mania, were more likely than patients with other Axis I diagnoses to report violence toward people just prior to admission (Tardiff \& Sweillam, 1980; Craig, 1982; Tardiff, 1984). There was an increased risk of violence in hospitals among psychiatric inpatients with organic mental disorders (Tardiff \& Sweillam, 1982; Miller et al., 1993; Convit et al., 1988).

Next I will present some of the more common neurological and medical disorders which have been found to be associated with violence. Violence caused by rare diseases have been presented in an earlier publication (Tardiff, 1998). There include brain tumors, encephalitis not due to AIDS, Wilsonís disease, Huntingtonís disease, sleep disorders, thyroid diseases, parathyroid diseases, vitamin deficiencies and toxins.

Violence and other behavioral problems are common among patients with dementia, especially Alzheimer's disease (Reisberg et al., 1987). Among patients in a long-stay psychogeriatric unit in a three day period of time $45 \%$ of the patients with Alzheimer's disease were aggressive with $4 \%$ rated as severely aggressive and
$11 \%$ as moderately aggressive (Patel \& Hope, 1992). In -another study of demented outpatients, 34\% were found to have a history of physical aggression, most often occurring when the patient was told to do something (Hamel et al., 1990). Other studies have found that patients with Alzheimer's disease were most likely violent when they were delusional or misidentified the environment as being threatening to them (Deutsch et al., 1991; Reisberg \& Ferris, 1985).

AIDS infection of the brain can cause dementia with irritability, agitation, paranoid delusion and violence (Snider et al., 1983; Nurnberg et al., 1984). AIDS encephalitis can cause other psychopathology such as mania, depression and confusion. The picture can be very complex since this population of patients are at risk for other disorders which are related to violence, namely substance abuse and antisocial personality. Blunt trauma to the brain often results in irritability and aggressiveness, from $70 \%$ to nearly $100 \%$ of the time (McKinlay et al., 1981; Rao et al., 1995). Agitation begins in the first few weeks after the brain injury and may persist for several months (Brook et al., 1992). At the slightest provocation, the patient is violent toward other persons or property. Some patients with traumatic brain injury become delirious with delusions, hallucinations and confusion which further lead to violence. Long term changes in personality and intellect can predispose to violence for years (Fordyce et al., 1993).

Intellectually impaired individuals with mental retardation or autism can be violent, generally in proportion to the severity of the impairment. Much of the violence occurs among inpatients who kick, punch and push other patients or staff (Glaziuddin \& Ghaziuddin, 1992). Intellectually impaired patients who live in the community with family or supervised housing also have a high rate of violence toward family and roommates (Bouras \& Drummond, 1992).

Hypoxia is insufficient oxygen in the blood caused by heart or lung disease. Electrolyte imbalance is abnormally low or high levels of elements such as sodium and calcium in the blood caused by kidney disease or intravenous transfusion. Hypoxia and electrolyte imbalance affects the functioning of the brain which in turn produces delirium with fluctuating levels of consciousness, disorientation, confusion, hallucinations, delusions and combativeness (Kutzer, 1990). Violence can occur because of emotional instability and general agitation or from paranoid delusional thinking or misperception of the environment.

In conclusion the few untreated prevalence studies of 
violence indicate that having a mental disorder increases oners risk of being violent.

The presence of psychosis with delusions and/or hallucinations increases the risk of violence. An acute psychotic state found in schizophrenia, mania, delusional disorder or organic mental disorder reflects a high risk of violence if the patient is thinking about violence. Manic patients can be violent when they feel contained or trapped.

Patients with antisocial and borderline personality disorders are often violent as a form of manipulation to get what they want. Violence is not followed by remorse for such behavior. Patients with intermittent explosive disorder are remorseful after being violent. Between violent episodes they are more stable than patients with antisocial or borderline personality disorders. Patients with post-traumatic stress disorder can be violent often when confronted with the same or similar cues related to the original traumatic event.

Alcohol disinhibits and impairs cognition, resulting in violence. Drugs that produce violence are cocaine, amphetamines, PCP and anabolic steroids. Polysubstance abuse and alcohol further increase a patientís risk of violence. Gross impairment of the brain by neurological and medical diseases is associated with increased risk of violence. The more common diseases with violence are dementia, AIDS encephalitis, head trauma, developmental disorders, hypoxia and electrolyte imbalances.

\section{REFERENCES}

American Psychiatric Association 1994). Diagnostic and Statistical Manual of Mental Disorders, 4th.ed. (DSM-IV). APA: Washington, DC.

Arango C., Barba A.C., Gonzalez-Salvador T. \& Ordonez A.C. (1999). Violence in inpatients with schizophrenia: a prospective study. Schizophrenia Bulletin 25, 493-503.

Bach-y-Rita G., Lion J.R. \& Clement C.E. (1971). Episodic dyscontrol: a study of 130 violent patients. American Journal of Psychiatry 127, 1473-1478.

Bailey D.N. (1979), Phencyclidine abuse, clinical findings and concentrations in biological fluids after nonfatal intoxication American Journal of Clinical Pathology 72, 795-799.

Benjarnin L (1993). Interpersonal Treatment of Personality Disorders. Guilford: New York.

Benjaminsen S., Botzsche-Larsen K., Norrie L., Harder L. \& Luxhoi A. (1996). Patient violence in a psychiatric hospital in Denmark. Rate of violence and relation to diagnosis. Nordic Journal of Psychiatry 50, 233-242.

Binder R.L. \& McNiel D.E. (1988). Effects of diagnosis and context on dangerousness. American Journal of Psychiatry 145, 728-732.

Bland R. \& Orn H. (1986). Family violence and psychiatric disorder.
Canadian Journal of Psychiatry 31, 129-137.

Bouras N. \& Drummond C. (1992). Behaviour and psychiatric disorders of people with mental handicaps living in the community. Journal of Intellectual Disability Research 36, 349-357.

Brody S.L. (1990). Violence associated with acute cocaine use in patients admitted to a medical emergency department. NIDA Research Monograph 103, 44-59.

Brooke M.M., Questad K.A., Patterson D.R. \& Bashak K.J. (1992). Agitation and restlessness after closed head injury: a prospective study of 100 consecutive admissions. Archives of Physical Medicine Rehabilitation 73, 320-323.

Choi P.Y.L., Parrott A.C. \& Cowan D. (1989). High dose anabolic steroids in strength athletes: effects upon hostility and aggression. Journal of Psychopharmacology 3, 102.

Collins J.J. \& Schlenger W.E. (1988). Acute and chronic effects of alcohol use on violence. Journal of Studies on Alcoholism 49, 516521.

Convit A., Isay D. \& Gadioma R. (1988). Underreporting of physical assaults in schizophrenic inpatients. Journal of Nervous and Mental Disease 176, 507-509.

Craig T.J. (1982). An epidemiologic study of problems associated with violence among psychiatric inpatients. American Journal of Psychiatry 139, 1262-1266.

Davis S. (1991). Violence by psychiatric inpatients: a review. Hospital and Community Psychiarry 42, 585-590.

Denison M.E., Paredes A. \& Booth J.B. (1997). Alcohol and cocaine interactions and aggressive behaviors. Recent Developments in Alcoholism 13, 283-303.

Deutsch L.H., Bylsma F.W., Rovner B.W., Steele C.S. \& Folstein M.F. (1991). Psychosis and physical agitation in probable Alzheimeris disease. American Journal of Psychiatry 148, 1159-1163.

Ellinwood E.H. jr.(1971). Assault and homicide associated with amphetamine abuse. American Journal of Psychiatry 127, 11701175.

Eronen M., Hakola P. \& Tiihonen J. (1996). Mental disorders and homicidal behavior in Finland. Archives of General Psychiatry 53 , 497-501.

Fordyce D.J., Roueche J.R. \& Prigatano G.F. (1993). Enhanced emotional reactions in chronic head trauma patients. Journal of Neurology, Neurosurgery and Psychiatry 46, 620-624.

Geller M.P. (1980). Sociopathic adaptation by psychotic patients. Hospital and Community Psychiatry 31, 108-112.

Ghaziuddin M. \& Ghaziuddin N. (1992). Violence against staff by mentally retarded inpatients. Hospital and Community Psychiatry 43, 503-504.

Giannini A.J., Miller N.S., Lioselle R.H. \& Turner C.E. (1993). Cocaine-associated violence and relationship to route of administration. Joumal on Substance Abuse Treatment 10, 67-69.

Hamel M., Gold D.P., Andres M., Reis M., Dastoor D., Grauer H. \& Bergman H. (1990). Predictors and consequences of aggressive behavior by community-based dementia patients. Gerontologist 30 , 206-211.

Hare R.D., Harpur T.J., Hakstian A.R., Forth A.E., Hart S.D. \& Newman J.P. (1990). The revised Psychopathology Checklist: description, statistics, reliability and factor structure. Psychological Assessment 2, 338-341.

Hellerstein D., Frosch W. \& Koenigsberg H.W. (1987). The clinical significance of command hallucinations. American Journal of Psychiatry 144, 219-221.

Hodgins S. (1992). Mental disorder, intellectual deficiency and crime evidence from a birth cohort. Archives of General Psychiatry 49, 
476-483.

Humphreys M.S., Johnstone E.C. \& MacMillan J.F. (1992). Dangerous behavior preceding first admission for schizophrenia. British Journal of Psychiatry 161, 501-505.

Ito T.A., Miller N. \& Pollock V.E. (1996). Alcohol and aggression: A meta-analysis on the moderating effects of inhibitory cues, triggering events and self-focused attention. Psychological Bulletin 120.60-82.

Janofsky J.S., Spears S. \& Neubauer D.N. (1988). Psychiatristsí accuracy in predicting violent behavior on an inpatient unit. Hospital and Community Psychiatry 39, 1090-1094.

Jordan B.K., Marmar C.R. \& Fairbank J.A. (1992). Problems in families of male Vietnam veterans with posttraumatic stress disorder. Journal of Consulting and Clinical Psychology 60, 916926.

Junginger J. (1995). Command hallucinations and the prediction of dangerousness. Psychiatric Services, 46, 911 -914.

Krakowski M., Volavka J. \& Brizer D. (1986). Psychopathology and violence: A review of literature. Comprehensive Psychiatry 27, $131-148$.

Krakowski M., Convit A. \& Jaeger J. (1989). Neurological impairment in violent schizophrenic inpatients. American Journal of Psychiatry $146,849-853$

Kutzer D.J. (1990). Psychobiological factors in violent behavior. Violent Behavior. Vol I. In Assessment and Intervention (ed. L.J. Hertzberg. G.F. Ostrum and J.R. Field). PMA Publishing: New' York.

Lasko N.B., Gurvits T.V. \& Kuhne A.A. (1994). Aggression and its correlates in Vietnam veterans with and without chronic posttraumatic stress disorder. Comprehensive Psychiatry 35, 373381.

Lee H.K., Villar O. \& Juthani N. (1989). Characteristics and behavior of patients involved in psychiatric ward incidents. Hospital and Community Psychiatry 40, 1295-1297.

Lindqvist P. \& Allebeck P. (1990). Schizophrenia and assaultive behaviour: the role of alcohol and drug abuse. Acta Psychiatrica Scandinavica 82, 191-195.

Link B.G., Andrews H. \& Cullen F.T. (1992). The violent and illegal behavior of mental patients reconsidered. American Sociological Review 57, 275-292.

Lowenstein D.H., Massa S.M, Rowbotham M.C., Collins S.D., McKinney H.E. \& Simon R.P. (1987). Acute neurologic and psychiatric complications associated with cocaine abuse. American Journal of Medicine 83, 841-846.

Lowenstein M., Binder R.L. \& McNiel D.E. (1990). The relationship between admission symptoms and hospital assaults. Hospital and Community Psychiatry 41, 311-313.

Manschreck T.C., Laughery J.A., Weisstein C.C.. Allen B., Humbelstone M., Neville H., Podlewski H. \& Mitra N. (1988). Characteristics of freebase cocaine psychosis. Yale Journal of Biology Medicine 61, 115-122.

McCormick R.A. \& Smith M. (1995). Aggression and hostility in substance abusers: the relationship to abuse patterns, coping style, and relapse triggers. Addictive Behaviors 20, 555-562.

McKinlay W.W., Brooks D.N. \& Bond M.R. (1981). The short-term outcome of severe blunt head trauma as reported by relatives of injured persons. Journal of Neurology. Neurosurgery and Psychiatry 44, 527-533.

Mendoza R. \& Miller B.L. (1992). Neuropsychiatric disorders associated with cocaine use. Hospital and Community Psychiatry 43. 677-678.
Miller R.J., Zadolinnyj K. \& Hafner R.J. (1993). Profiles and predictors of assaultiveness for different psychiatric ward populations. American Journal of Psychiatry 150, 1368-1373.

Monroe R.R. (1970). Episodic Behavioral Disorders. Harvard University Press: Cambridge, MA.

Murdoch D., Pihl R.O. \& Ross D. (1990). Alcohol and crimes of violence: present issues. International Journal of Addiction 25, 1065-1081.

Nurnberg H.G., Prudic J.. Fiori M. \& Freedman E.P. (1984). Psychopathology complicating acquired immune deficiency syndrome (AIDS). American Journal of Psychiatry 141, 95-96.

Patel V. \& Hope R.A. (1992). Aggressive behaviour in elderly psychiatric inpatients. Acta Psychiatrica Scandinavica 85, 131-135.

Perry J.C. \& Herman J. (1993). Trauma and defense in the ideology of borderline personality disorder. In Borderline Personality Disorder: Etiology and Treatment (ed. J Paris), pp 135-139. American Psychiatric Press: Washington, DC.

Peterson J.B., Rolhfleisch J., Zelazo P.D. \& Pihl R.O. (1990). Acute intoxication and cognitive functioning. Journal of Studies Alcoholism 51, 114-122.

Pope H.G. Jr. \& Katz D.L. (1990). Homicide and near-homicide by anabolic steroid users. Journal of Clinical Psychiatry 51, 28-31.

Raine A. (1993). The Psychopathology of Crime. Criminal Behavior as a Clinical Disorders. Academic Press: San Diego, CA.

Rao N., Jellinek H.M. \& Woolston D.C. (1985). Agitation in closed head injury: haloperidol effects on rehabilitation outcome. Archives of Physical Medicine and Rehabilitation 66, 30-34.

Reisberg B. \& Ferris S.H. (1985). A clinical rating scale for symptoms of psychosis in Alzheimerís disease. Psychopharmacology Bulletin 21, 101-104.

Reisberg B., Borenstein J., Salbo S. \& Ferris S.H. (1987). Behavioral symptoms in Alzheimer's disease: phenomenology and treatment. Journal of Clinical Psychiatry 48, Suppl. 5, 9-15.

Rogers R., Nussbaum D. \& Gillis R. (1988). Command hallucinations and criminality: a clinical quandary. Bulletin of American Academy of Psychiatry and the Law 16, 251-258.

Rossi A.M., Jacobs M., Monteleone M., Olsen H., Surber R.W., Winkler E.L. \& Wommack A. (1986). Characteristics of psychiatric patients who engage in assaultive or other fear-inducing behaviors. Journal of Nervous and Mental Disease 174, 154-160.

Salloum I.M., Daley D.C. \& Cornelius J.R. (1996). Disproportionate lethality in psychiatric patients with concurrent alcohol and cocaine abuse. American Journal of Psychiatry 153, 953-955.

Schulte H.M., Hall M.J. \& Boyer M. (1993). Domestic violence associated with anabolic steroid abuse (letter). American Journal of Psychiatry 150, 348.

Snider W.D., Simpson D.M., Nielson S., Gold J.W.M., Metroka C.E. \& Posner J.B. (1983). Neurological complications of acquired immune deficiency syndrome: Analysis of 50 patients. Annals of Neurology 14, 403-418.

Steadman H.J., Mulvey E.P., Monahan J., Robbins P.C., Appelbaum P.S., Grisso T.. Roth L.H. \& Silver E. (1998). Violence by people discharged from acute psychiatric inpatient facilities and by others in the same neighborhoods. Archives of General Psychiarry 55, 393-401.

Stone M.H. (1990). The Fate of the Borderline Patient: Successful Outcome in Psychiatric Practice. Guilford: New York.

Su T., Pagliaro M. \& Schmidt P.J. (1993). Neuropsychiatric effects of anabolic steroids in male normal volunteers. Journal of the American Medical Association 269, 2760-2764.

Swanson J.W., Holzer C.E., Ganju V.K. \& Jono R.T. (1990). Violence

Epidemiologia e Psichiatria Sociale, 9, 4, 2000 
and psychiatric disorder in the community: Evidence from the epidemiologic catchment area surveys. Hospital and Community Psychiatry 41, 761-770.

Tam E., Engelsmann F. \& Fugere R. (1996). Patterns of violent incidents by patients in a general hospital psychiatric facility. Psychiatric Services 47, 86-88.

Tardiff K. (1984). Characteristics of assaultive patients in private hospitals. American Journal of Psychiatry 141, 1232-1235.

Tardiff K. (1998). Unusual diagnoses among violent patients. Psychiatric Clinics of North America 21, 567-579.

Tardiff K. \& Koenigsberg H. (1985). A study of assaultive behavior among psychiatric outpatients. American Journal of Psychiatry 142, 960-963.

Tardiff K. \& Sweillam A. (1980) Assault, suicide, and mental illness. Archives of General Psychiatry 37, 164-169.

Tardiff K. \& Sweillam A. (1982). Assaultive behavior among chronic inpatients. American Journal of Psychiatry 139, 212-215.

Tardiff K., Marzuk P.M., Leon A.C., Portera L. \& Weiner C. (1997a). Violence by patients admitted to a private psychiatric hospital.
American Journal of Psychiatry 154, 88-93.

Tardiff K., Marzuk P.M., Leon A.C. \& Portera L. (1997b). A prospective study of violence by psychiatric patients after hospital discharge. Psychiatric Services 48, 678-681.

Taylor P.J. (1986). The risk of violence in psychotics. Integrative Psychiatry 4, 12-16.

Taylor P.J. (1997). Mental disorder and risk of violence. International Review of Psychiatry 9, 157-161.

Taylor S.P. \& Leonard K.E. (1983). Alcohol and human aggression. In Aggression: Theoretical and Empirical Review's, Vol. 2 (ed. R.G. Green and E.I. Donnerstein), pp. 77-101. Academic Press: New York.

Virkkunen M. \& Linnoila M. (1990). Serotonin in early onset, male alcoholics with violent behaviour. Annals Medicine 22, 327-331

Widom C.S. (1989). Does violence beget violence? A critical examination of the literature. Psychological Bulletin 114, 68-79.

Yesavage J.A. (1983). Bipolar illness: Correlates of dangerous inpatient behaviour. British Journal of Psychiatry 143, 554-557. 